\title{
A Cross-Sectional Survey of Practice Patterns and Selected Demographics of Respiratory Therapists in India
}

\author{
Madhuragauri S Shevade, Rajiv C Yeravdekar, and Sundeep S Salvi
}

\begin{abstract}
BACKGROUND: Respiratory therapy was introduced to India in 1995. Respiratory therapists (RTs) work alongside doctors in hospitals. Of the 993 universities in India, a few have bachelor's or master's programs in respiratory therapy, but no studies have examined the demographics, geographical spread, or skills used by these RTs. This study assessed the demographics and services offered by RTs in India. METHODS: This was a cross-sectional study based on a survey administered on paper, by telephone, or online. RTs were selected by convenience sampling from institutional databases and from WhatsApp groups of RTs in India, as well through snowball sampling of co-workers. A link to the online survey was shared on the author's personal social media channels. Of the invited RTs, 465 consented and participated; of those, 237 answered all questions. RESULTS: Of the 237 respondents completing the survey, $73 \%$ had bachelor's degree, $16.5 \%$ had a master's degree, $4.6 \%$ had a diploma, $2.5 \%$ had mixed qualifications, $1.7 \%$ had post graduate diploma, $0.8 \%$ had a certificate, $0.4 \%$ had a master of business administration degree, and $0.4 \%$ had a PhD degree. Almost all $\mathbf{( 9 6 . 6 \% )}$ ) worked as an RT or in a job that required respiratory therapy knowledge. Although individuals may have had multiple job roles, $77.6 \%$ worked as a hospital staff RT. The least frequently performed competencies were recommending diagnostic procedures, using evidence-based principles, initiating and conducting patient and family education, and administering home care and pulmonary rehabilitation; the most frequently performed competencies were support oxygenation and ventilation, ensuring infection control, and maintaining a patent airway. CONCLUSIONS: Most subjects were employed in south India and had a bachelor's degree. They worked as staff RTs with a focus on the acute care environment. Pneumonia, asthma, COPD, and ARDS were the most commonly managed diseases. Competencies such as recommending procedures, planning and providing pulmonary rehabilitation, and administering home-based care were the least frequently performed. Key words: respiratory therapy; India; respiratory therapists; allied health; clinical competency; respiratory health. [Respir Care 2021;66(1):66-72. (C) 2021 Daedalus Enterprises]
\end{abstract}

\section{Introduction}

Respiratory diseases are among the leading causes of suffering and death worldwide. ${ }^{1-3}$ In India, they are the second leading cause of disability and death. Acute and chronic infective and chronic noncommunicable diseases such as

\footnotetext{
Ms Shevade and Dr Salvi are affiliated with the Training Programs Division, Chest Research Foundation, Marigold Premises, Pune, Maharashtra, India. Ms Shevade and Dr Yeravdekar are affiliated with the Faculty of Health and Biological Sciences, Symbiosis International Deemed University, Pune, Maharashtra, India.
}

Ms Shevade presented a version of this paper as a poster at AARC Congress 2019, held November 9-12, 2019, in New Orleans, Louisiana. asthma, COPD, interstitial lung diseases, and lung cancers are believed to be the primary contributors to the global burden of lung diseases. ${ }^{1-3}$ Around $50 \%$ of patients who

\footnotetext{
Supplementary material related to this paper is available at http://www. rcjournal.com.

The authors have disclosed a relationship with Cipla Foundation.

Correspondence: Madhuragauri Shevade MSc RRT RRT-NPS, Chest Research Foundation, Pune, India and Faculty of Health and Biological Sciences, Symbiosis International Deemed University, Pune, India. E-mail: madhuragauri@gmail.com.
}

DOI: $10.4187 /$ respcare. 07823 


\section{Practice Patterns and Demographics of RTs in India}

visit a primary care physician in India do so for respiratory symptoms, and about half of these do so for chronic respiratory diseases. ${ }^{4,5}$

India is the world leader in deaths due to chronic respiratory diseases, with an estimated 100 million people affected. ${ }^{2,6,7}$ Obstructive airway diseases including COPD and asthma dominate the burden of disease and have a substantial impact on the country's economy. ${ }^{6,8}$ Given the vast and growing number of patients with chronic respiratory disease in India, accompanied by limited resources of welltrained respiratory physicians and nurses, the quality of care of both out-patient and hospitalized patients with respiratory diseases is significantly compromised. A huge gap exists between the number of patients and the number of physicians and nurses available to manage them, leading to underdiagnosis and undermanagement of chronic respiratory disease. ${ }^{4}$ The scarcity of qualified doctors demands a middle tier of specially trained personnel who can bridge the gap between doctors and respiratory patients.

The middle-tier profession of respiratory therapists (RTs) helps diagnose, treat, and manage patients with cardiopulmonary diseases alongside physicians. Respiratory therapy profession originated in 1943 according to the American Association for Respiratory Care (https://www. aarc.org/aarc/timeline-history, Accessed April 25, 2020) due to a need identified by physicians in the United States. ${ }^{9}$ The field has since grown to become an essential part of health care with around 134,000 registered RTs working in the United States in 2018. ${ }^{9,10}$ RTs work in both acute and chronic care settings, and they can be employed as clinical specialists, as faculty at universities and colleges, and as health care researchers. The success of the field and the growing need for RTs has been noted by other countries as well, with many now employing and offering various training programs for respiratory therapy. ${ }^{9}$

In India, the profession of respiratory therapy was established by Dr Ramkumar Venkateswaran, an anesthesiologist from Manipal University who enrolled at Loma Linda University, California, to understand its RT program.9.11 After he completed the program, he returned to India in 1995 to found a formal degree program in respiratory therapy, which is still running successfully. At the same time, several other pulmonologists at different institutions initiated similar programs at the certificate level. This created a ripple effect, and many other universities began offering RT programs. To date, of 993 universities in India, around 12 offer an RT program, with a total of 1,000 graduates since $1995 .{ }^{12}$ The curricula are largely based on what is followed in the United States.

Respiratory therapy in India is still in its infancy. The field has grown over the years, but not in a structured or uniform manner. It is time to take stock of what work RTs are doing in India, where they are located, their educational backgrounds, and their current job profiles. A better

\section{QUICK LOOK}

\section{Current knowledge}

Respiratory therapy has been in existence in India for the past 25 years. Several universities offer formal degree, diploma, and certificate programs in respiratory therapy based on the curriculum followed in the United States of America. The training provided is unstructured, and the number of universities with these programs is increasing every year.

\section{What this paper contributes to our knowledge}

This paper provides a better idea of the demographic background of respiratory therapists in India. Respiratory therapists are mostly located in the south of the country and working as staff therapists in adult ICUs. They commonly manage pneumonia, asthma, COPD, and ARDS. Respiratory therapists use most of their skills in their roles, except for recommending procedures, planning and providing pulmonary rehabilitation, and administering homebased care, which are infrequently performed.

understanding of this will help create a formal structure for RT training programs in India and advance the field so that the quality of care of patients with respiratory diseases can be improved. This will have direct and indirect effects on the suffering and deaths associated with chronic respiratory diseases. This study aimed to understand the demographic details and the competencies of RTs currently working in India.

\section{Methods}

This cross-sectional, questionnaire-based survey was conducted at the Chest Research Foundation, Marigold Premises, in Pune, Maharashtra, India, as a part of a larger project examining the evolution, current practices, and future needs of respiratory therapy in India. The study was conducted across India from February 2019 to September 2019. The study was approved by the Chest Research Foundation's institutional ethics committee as well as the Symbiosis International University's independent ethics committee.

Individuals who had graduated from any institution offering RT programs with a certificate, diploma, Bachelor of Science (BS), Master of Science (MSc) or Doctor of Philosophy $(\mathrm{PhD})$ degree were invited to participate in the study. RTs from the Chest Research Foundation database, the International RT WhatsApp group of India, and connections on the author's social media accounts participated in the study. Respondents were requested to share the contact details of their RT colleagues and friends. These new RTs 


\section{Practice Patterns and Demographics of RTs in India}

were also contacted by telephone, and their responses were obtained. All other allied health professionals specializing in respiratory care, such as nurses and physiotherapists, current students pursuing RT programs, and RTs working outside India were excluded from this study.

Based on the number of institutes offering RT programs and the total annual intake of students, an estimated 1,000 students have graduated either with a certificate or a BS, MSc, or PhD degree in India. Subjects were selected using a convenience sampling strategy due to the lack of any readily available database. At the time of the study, the Indian Association of Respiratory Care had around 300 members, including life members and student members. However, a list of these members was not available. Further, educational institutions were reluctant to share alumni details due to privacy regulations. Nevertheless, we were able to approach many members through other channels of communication, such as telephone calls and social media messaging.

\section{Study Tool}

A simple, multiple-choice questionnaire-based survey was designed by the study team to capture the subjects' demographic details, location, educational qualifications, experience, current job profile, and how frequently they utilize the competencies that they learned during their training (see the supplementary materials at http://www.rcjournal.com). The section on demographic details, location, and qualification was a mix of open and closed questions. Nine closed multiple-choice questions were divided into Part A and Part B on experience, job profile, and utilization of competencies.

We shared this survey with a team of experts that included physicians, senior RTs, experienced researchers, and statisticians associated with respiratory therapy for their feedback. The survey was vetted by experts twice to refine the questions and responses, with suggested changes incorporated into the survey. An online version of the survey was designed in Survey Monkey and sent to $10 \mathrm{RTs}$; their responses and feedback were used to assess the format, logic checks, clarity of responses, and time required to answer the questions.

When the data collection was initiated, the study was explained to subjects, and their written, verbal, or online consent was obtained before the questionnaire was given. The questionnaire was administered either on paper, by telephone, or online.

A link to the online survey was also shared on the author's personal social media channels, such as Facebook, Twitter, and LinkedIn. Of the 502 RTs who were invited, 465 consented and participated in the study; of those, 237 answered all of the questions (Fig. 1).The remaining 228 were excluded from analysis due to the following reasons:

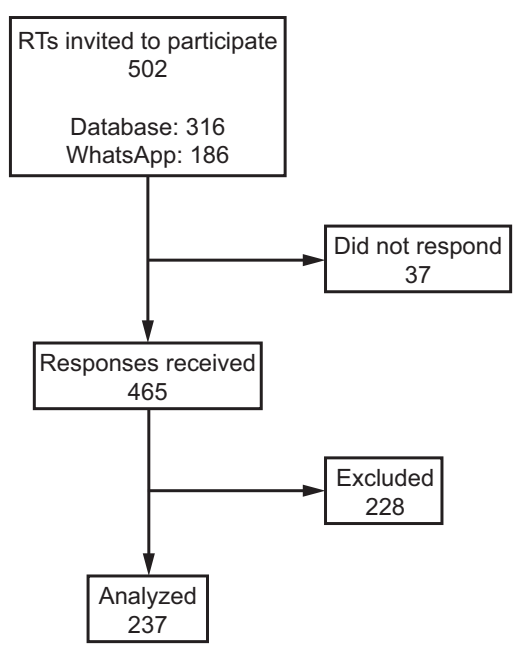

Fig. 1. Flow chart. RTs = respiratory therapists.

No attempt after consent page $(\mathrm{n}=118)$, incomplete responses $(n=51)$, subjects worked outside India $(n=27)$, duplicate responses $(n=20)$, student responses $(n=8)$, and no consent given $(n=4)$.

\section{Statistical Analysis}

The data that were collected on paper was manually entered into the Survey Monkey software. The data were checked for completeness and fulfillment of inclusion criteria before entry. Logic checks and minimum requirements for questions were incorporated when designing the online version, which helped avoid any data entry errors.

The final data file was imported into an analyzable format for data cleaning and management. Twenty paperbased questionnaires were randomly selected after entry into the data file and manually checked for errors while entering data points, resulting in an error rate of $<0.7 \%$. The cleaned data sheet was locked for analysis, and simple descriptive statistics were performed with SPSS 26 (IBM, Armonk, New York).

\section{Results}

Of the 237 respondents, $54.9 \%$ were women. The mean \pm SD age of the 237 subjects was $25.7 \pm 5.01 \mathrm{y}$. The average clinical experience was $3.3 \pm 4.0 \mathrm{y}$, and $30 \%$ had teaching experience of $3.2 \pm 3.6 \mathrm{y}$. Table 1 on subject demographics lists the number of respondents according to the distribution by state.

\section{Education and Work}

Out of the 237 respondents, $73 \%$ had a bachelor's degree; $16.5 \%$ had a master's degree; $4.6 \%$ had a 


\section{Practice Patterns and Demographics of RTs in India}

Table 1. Subject Demographics

\begin{tabular}{lc}
\hline \hline Gender & \\
Female & $130(54.9)$ \\
Male & $107(45.1)$ \\
Respondent's Location (state in India) & \\
Maharashtra & $51(21.5)$ \\
Karnataka & $76(32.1)$ \\
Andhra Pradesh & $1(0.4)$ \\
Chandigarh & $1(0.4)$ \\
Delhi & $2(0.8)$ \\
Kerala & $52(21.9)$ \\
Meghalaya & $1(0.4)$ \\
Uttar Pradesh & $3(1.3)$ \\
Odisha & $2(0.8)$ \\
Tamil Nadu & $41(17.3)$ \\
Telangana & $5(2.1)$ \\
West Bengal & $1(0.4)$ \\
Rajasthan & $1(0.4)$ \\
Highest Qualification & \\
Bachelor of Science & $173(73.0)$ \\
Master of Science & $39(16.5)$ \\
Diploma & $11(4.6)$ \\
Mixed & $6(2.5)$ \\
Post Graduate Diploma & $4(1.7)$ \\
Certificate & $2(0.8)$ \\
Master of Business Administration & $1(0.4)$ \\
Doctor of Philosophy & $1(0.4)$ \\
\hline Data are presented as $n$ (\%). Percentages may not total 100 due to rounding. & \\
\hline & \\
\hline
\end{tabular}

diploma; $2.5 \%$ had mixed qualifications; $1.7 \%$ had post graduate diploma; $0.8 \%$ had a certificate; $0.4 \%$ had a master of business administration degree; and $0.4 \%$ had a $\mathrm{PhD}$ (Table 1). Each university had unique nomenclature for their degree course, including Respiratory Care Technology, Respiratory Therapy, Medical Technology, Allied Health Science in Respiratory Therapy, and Respiratory Care Technician.

Almost all subjects (96.6\%) worked as an RT or in a job role that required RT knowledge, while $3.4 \%$ had quit, were unemployed, or had changed careers (eg, stay-athome parent, homemaker, flight attendant). Subjects had multiple job roles; $77.6 \%$ worked as staff RTs in hospitals, and other job roles included teaching faculty (17.7\%), clinical specialists in a company $(11.4 \%)$, researchers $(10.1 \%)$, managers in a company $(5.1 \%)$, freelance therapists (4.6\%), managers at hospitals (2.5\%), and other (8.4\%).

Subjects were asked about the different areas where they spent their typical work week. They were asked to divide their time within areas that were listed so that the total was $100 \%$. They spent $52.1 \pm 31 \%$ of their time in adult intensive care units (ICUs), $7.0 \pm 9.2 \%$ in emergency rooms, $6.9 \pm 14.5 \%$ in pulmonary function testing units, $5.8 \pm 13.0 \%$ in pediatric ICUs, $6.1 \pm 12.5 \%$ in neonatal ICUs, $5.4 \pm 17.0 \%$ in universities, $3.9 \pm 9.2 \%$
Table 2. Percentage of Time where Participants Spent Their Time by Work Area

\begin{tabular}{lccc}
\hline \hline \multicolumn{1}{c}{ Work Area } & Minimum & Maximum & Mean \pm SD \\
\hline Adult ICU* & 0 & 100 & $52.2 \pm 31.1$ \\
Neonatal ICU & 0 & 100 & $6.1 \pm 12.5$ \\
Pediatric ICU & 0 & 100 & $5.8 \pm 13.0$ \\
Emergency/trauma/casualty & 0 & 50 & $7.0 \pm 9.2$ \\
Out-patient department & 0 & 60 & $3.9 \pm 9.2$ \\
Pulmonary function test lab & 0 & 100 & $6.9 \pm 14.5$ \\
Home care & 0 & 70 & $1.6 \pm 8.0$ \\
University & 0 & 100 & $5.4 \pm 17.0$ \\
Research center & 0 & 100 & $3.3 \pm 14.7$ \\
Multinational company & 0 & 100 & $3.8 \pm 16.6$ \\
Other & 0 & 100 & $2.3 \pm 12.5$ \\
Not applicable & 0 & 100 & $1.7 \pm 12.9$ \\
& & & \\
Valid $N$ (listwise) $=236$ respondents $(1$ missing). & \\
*Includes medical ICUs, cardiac care units, intensive critical care units, and high-dependence \\
units. \\
\hline
\end{tabular}

in out-patient departments, and $3.8 \% \pm 16.6 \%$ at multinational companies, $3.3 \% \pm 14.7 \%$ at research centers, $1.6 \% \pm 8.0 \%$ providing home care, and $2.3 \% \pm 12.5 \%$ at other areas (Table 2).

\section{Use of Competencies}

Subjects who worked in hospitals or respiratory clinics or as freelance therapists were asked about which items from a list of competencies they performed (Table 3). A question on the types of diseases managed revealed that they managed most of the listed diseases (Table 4). Lastly, subjects were asked how often they performed each listed skill at least once a week (Table 5). The least frequently performed competencies were recommending of diagnostic procedures $(39.2 \%)$, using evidence-based principles (40.1\%), initiating and conducting patient and family education $(27.8 \%)$, and administering home care $(16 \%)$ and pulmonary rehabilitation $(22.8 \%)$, while the most performed competencies were support oxygenation and ventilation $(90.3 \%)$, ensuring infection control $(81.9 \%)$, and maintaining a patent airway $(81 \%)$.

\section{Discussion}

This is the first study to comprehensively examine RTs in India in terms of their background, where they work, and what work they perform. It gives a current overview of the profession in India. Despite the profession existing for the last 25 years, no registry or official information is available on RTs. Creating a central database is therefore imperative to understand RTs in India and to help with training and employment. 
Practice Patterns and Demographics of RTs in India

Table 3. Competencies Performed by Hospital or Clinic Staff RTs or Freelance RTs

\begin{tabular}{lc}
\hline \hline \multicolumn{1}{c}{ Competencies } & $\begin{array}{c}\text { Respondents Who Performed } \\
\text { the Competency }\end{array}$ \\
\hline Mechanical ventilation & $204(92.7)$ \\
Airway management & $197(89.5)$ \\
Oxygen therapy & $196(89.1)$ \\
Cardiopulmonary resuscitation & $186(84.5)$ \\
Bronchial hygiene therapy & $184(83.6)$ \\
Equipment maintenance & $163(74.1)$ \\
Inhalation therapy & $180(73.5)$ \\
Objective testing & $119(54.1)$ \\
Pulmonary rehabilitation & $120(54.5)$ \\
Counselling & $104(47.3)$ \\
Sleep studies & $89(40.5)$ \\
Home based care & $55(25.0)$ \\
De-addiction programs & $37(16.8)$ \\
Other & $22(8.60)$ \\
\hline Data are presented as $n(\%)$. & \\
\hline
\end{tabular}

Although we believe we were able to contact $50 \%$ of RT graduates, the sample that we have collected cannot be generalized due to the lack of information on RTs in India. Our results indicate that most $(73.8 \%)$ of the RTs were in the southern region of India, with states including Karnataka and Maharashtra having the highest number of respondents. This may be because these states have the highest number of medical colleges in India according to the Medical Council of India (https://www.mciindia.org/cms/information-desk/forstudents-to-study-in-india/list-of-college-teaching-mbbs, Accessed April 25, 2020). In addition, the first institutions to offer RT training programs were in the southern states such as Karnataka. ${ }^{11,13,14}$ Most subjects (73\%) had a minimum of a bachelor's qualification, and $16.5 \%$ of those had a master's degree. This means that India is on the correct track in following international recommendations of having a bachelor's degree for entry to the profession. ${ }^{15,16}$

Subjects may have had multiple roles, but most (77.6\%) worked predominantly as hospital staff RTs. Most of their time $(52.1 \%)$ was spent in adult ICUs (including medical ICUs, cardiac care units, intensive critical care units, and high-dependence units). Respiratory therapy in India was started as a need-based program by physicians to manage patients with respiratory diseases in the ICU. ${ }^{11,13}$ RTs in India are known to work in the acute care setting, ${ }^{8}$ but this study is the first to quantify how much time is devoted to each area. Interestingly, $17.7 \%$ of RTs also work at universities as faculty, $11.4 \%$ are in the corporate sector as application specialists, and $5.1 \%$ work as product managers.

Pneumonia, asthma, COPD, and ARDS were the diseases most commonly managed by RTs. The rise in consumption of tobacco, indoor and outdoor air pollution, and
Table 4. Medical Conditions Managed by Respondents

\begin{tabular}{|c|c|}
\hline Medical Condition & $\begin{array}{l}\text { Respondents Who Managed } \\
\text { the Medical Condition }\end{array}$ \\
\hline Pneumonia & $207(87.3)$ \\
\hline Chronic asthma & 207 (87.3) \\
\hline Chronic COPD & 207 (87.3) \\
\hline COPD exacerbations & $205(86.5)$ \\
\hline Asthma exacerbations & $203(85.7)$ \\
\hline ARDS & $201(84.8)$ \\
\hline Adult & $195(82.3)$ \\
\hline Pulmonary edema & $193(81.4)$ \\
\hline Upper respiratory tracts infections & $192(81.0)$ \\
\hline Other lower respiratory tract infections & $188(79.3)$ \\
\hline Tuberculosis & 187 (78.9) \\
\hline Interstitial lung diseases & $184(77.6)$ \\
\hline Pleural diseases & $181(76.4)$ \\
\hline Pneumothorax & $178(75.1)$ \\
\hline Neuromuscular disorders & $178(75.1)$ \\
\hline Bronchiectasis & $176(74.3)$ \\
\hline Obstructive sleep apnea & $176(74.3)$ \\
\hline Pulmonary hypertension & $171(72.2)$ \\
\hline Pulmonary embolism & $171(72.2)$ \\
\hline Heart failure & $164(69.2)$ \\
\hline Cardiovascular & $163(68.8)$ \\
\hline Sepsis & $163(68.8)$ \\
\hline Cystic fibrosis & $156(65.8)$ \\
\hline Postoperative & $156(65.8)$ \\
\hline Shock & $155(65.4)$ \\
\hline Neurological disorders & $153(64.6)$ \\
\hline Kidney failure/kidney disease & $152(64.1)$ \\
\hline Trauma & $148(62.4)$ \\
\hline Lung cancer & $140(59.1)$ \\
\hline Immunocompromised & $136(57.4)$ \\
\hline General disorders & $132(55.7)$ \\
\hline Congenital cardiac defects & $132(55.7)$ \\
\hline Geriatric & $121(51.1)$ \\
\hline Drowning/near drowning & $120(50.6)$ \\
\hline Pediatric diseases & $87(36.7)$ \\
\hline Burn/burn injury & $77(32.5)$ \\
\hline Neonatal diseases & $74(31.2)$ \\
\hline Lung transplant & $72(30.4)$ \\
\hline Psychiatric disorders & $51(21.5)$ \\
\hline Others & $3(1.3)$ \\
\hline
\end{tabular}

occupational exposure increases the incidence of respiratory diseases. ${ }^{3}$ Among these diseases, asthma, COPD, respiratory infections, tuberculosis, and lung cancer are believed to be the primary contributors to the global burden of diseases. ${ }^{1,2}$ India is the world leader in deaths due to chronic respiratory diseases, with an estimated 100 million people suffering from these diseases. ${ }^{2,6,7}$ In India, common chronic respiratory diseases such as COPD and asthma dominate the burden of diseases. ${ }^{6,8}$ Although most subjects in this study spent their time working in the acute setting, 


\section{Practice Patterns and Demographics of RTs in India}

Table 5. Frequency of Skills Performed Per Week in Percentage.

\begin{tabular}{|c|c|c|c|c|c|c|}
\hline \multirow{2}{*}{ Type of Skill } & \multirow{2}{*}{ Missing } & \multicolumn{5}{|c|}{ Frequency of Skills Performed per Week } \\
\hline & & Always & Often & Rarely & Sometimes & Never \\
\hline Support oxygenation and ventilation & $1(0.4)$ & 90.3 & 3.4 & 0.0 & 0.4 & 5.5 \\
\hline Ensure infection control & NA & 81.9 & 7.6 & 3.8 & 0.8 & 5.9 \\
\hline Maintain a patent airway & $1(0.4)$ & 81.0 & 8.0 & 3.4 & 0.4 & 6.8 \\
\hline Perform airway clearance and lung expansion techniques & $2(0.8)$ & 76.8 & 11.4 & 3.4 & 0.8 & 6.8 \\
\hline Assist a physician/provider in performing procedures & $1(0.4)$ & 73.0 & 9.7 & 5.5 & 3.4 & 8.0 \\
\hline Gather clinical information & NA & 71.7 & 15.6 & 4.2 & 1.7 & 6.8 \\
\hline Evaluate procedure results & NA & 69.6 & 14.8 & 7.6 & 2.1 & 5.9 \\
\hline Perform procedures to gather clinical information & NA & 68.8 & 15.2 & 8.0 & 2.5 & 5.5 \\
\hline Assemble and troubleshoot equipment & NA & 68.8 & 16.9 & 7.2 & 0.4 & 6.8 \\
\hline Evaluate data in the patient record & NA & 67.9 & 16.0 & 6.8 & 3.4 & 5.9 \\
\hline Provide respiratory care techniques in high-risk situations & $1(0.4)$ & 67.5 & 14.8 & 7.2 & 2.1 & 8.0 \\
\hline Perform quality control procedures & $3(1.3)$ & 61.6 & 19.4 & 7.2 & 3.4 & 7.2 \\
\hline Administer medications and specialty gases & NA & 53.2 & 23.2 & 11.0 & 3.0 & 9.7 \\
\hline Ensure modifications made to respiratory care plan & $1(0.4)$ & 49.8 & 23.2 & 15.6 & 2.1 & 8.9 \\
\hline Utilize evidence-based medicine principles & $5(2.1)$ & 40.1 & 22.8 & 16.9 & 5.9 & 12.2 \\
\hline Recommend diagnostic procedures & $1(0.4)$ & 39.2 & 23.6 & 17.3 & 7.2 & 12.2 \\
\hline Initiate and conduct patient and family education & NA & 27.8 & 19.0 & 20.3 & 14.3 & 18.6 \\
\hline Plan and administer pulmonary rehabilitation & $2(0.8)$ & 22.8 & 13.1 & 17.7 & 15.2 & 30.4 \\
\hline Administer home-based care & $1(0.4)$ & 16.0 & 9.7 & 15.2 & 20.3 & 38.4 \\
\hline $\begin{array}{l}\text { Data are presented as } n(\%) \text { or percentage values. } \\
\text { NA }=\text { not applicable }\end{array}$ & & & & & & \\
\hline
\end{tabular}

they frequently managed chronic diseases. This highlights the need and creates an opportunity for RTs to expand their role beyond the acute environment and into the chronic disease management environment in India. They could also expand their role to include skills such as sleep studies and pulmonary rehabilitation.

Subjects were asked how often they performed tasks from a list developed based on the Therapist Multiple Choice Examination. ${ }^{17}$ The RTs always or often performed most of the listed competencies. Interestingly, however, they infrequently recommended diagnostic procedures, used evidence-based principles, initiated and conducted patient and family education, or administered home care or pulmonary rehabilitation. This may be because the health care system in India is driven by doctors due to the lack of a structured allied health council, and RTs are not given the autonomy to make recommendations or to counsel and educate patients. Pulmonary rehabilitation is an important component of chronic respiratory disease management. ${ }^{18,19}$ Despite India having the highest number of patients with COPD who could benefit from pulmonary rehabilitation, it is practiced very rarely, not only by RTs but also by physicians themselves. ${ }^{20-}$ ${ }^{23}$ Lack of awareness and problems in the implementation of the program might be why pulmonary rehabilitation is not practiced often by our subjects. ${ }^{23,24}$

This study has a few limitations. Initially, when the questionnaire was sent to RTs, they were intimidated and unsure of the questionnaire, leading to a poor response. This was because most of the respondents were young graduates without experience in participating in research. This limitation was overcome by conducting telephone interviews. Additionally, the universities did not share the details of their alumni, making it difficult to contact graduates from early cohorts who were not in touch with other RTs or had left India. Further, randomly selecting respondents was not possible due to the lack of information on the total number of RTs in India, the number of institutes training RTs or their numbers of graduates. A convenience sampling method was hence selected. Lastly, due to this lack of information, the results of this study cannot be generalized.

\section{Conclusions}

Our results indicate that most respondents are situated in the south region of India and predominantly had a BS degree. They worked as staff RTs with a focus on the acute environment. Pneumonia, asthma, COPD, and ARDS were the most commonly managed diseases. Among the competencies performed by RTs, they seldom recommended procedures, planned and provided pulmonary rehabilitation, or administered home-based care. There is a lack of literature on the status of the RT field in India. Based on the results of this study, a plethora of opportunities exists to conduct research, which may yield methods to improve the quality of care provided by RTs. With standardized training given to RTs and more awareness created about the profession, they can take a more active role in managing respiratory 


\section{Practice Patterns and Demographics of RTs in India}

disease patients and further benefit the Indian health care setting.

\section{ACKNOWLEDGMENTS}

The authors thank Sapna Madas and Nisha Kale of the Chest Research Foundation for their guidance and review of the statistical analysis. The authors also thank Symbiosis International University's respiratory therapy interns, Krishnan J Kesav, Mansi Chorghade, and Aditi Biswas, who helped with obtaining the contact details of potential respondents and the collection of their data.

\section{REFERENCES}

1. Ferkol T, Schraufnagel D. The global burden of respiratory disease. Ann Am Thorac Soc 2014;11(3):404-406.

2. Salvi S, Kumar GA, Dhaliwal RS, Paulson K, Agrawal A, Koul PA, et al. The burden of chronic respiratory diseases and their heterogeneity across the states of India: the Global Burden of Disease Study 1990-2016. Lancet Glob Health 2018;6(12):e1363-e1374.

3. Schluger NW, Koppaka R. Lung disease in a global context: a call for public health action. Ann Am Thorac Soc 2014;11(3):407-416.

4. Salvi S, Apte K, Madas S, Barne M, Chhowala S, Sethi T, et al. Symptoms and medical conditions in 204912 patients visiting primary health-care practitioners in India: a 1-day point prevalence study (the POSEIDON study). Lancet Glob Health 2015;3(12):e776-e784.

5. Shevade M, Apte K, Jadhav S, Madas S, Salvi S, Sorte R. What are the most common respiratory diseases encountered in clinical practice? Results of a pilot study in 737 Indian patients. Eur Respir J 2015;46(suppl 59):PA3864.

6. World Health Organization. The global impact of respiratory disease, second edition. Forum of International Respiratory Societies. 2017. Available at: http://www.who.int/gard/publications/the_global_impact_ of_respiratory_disease.pdf. Accessed April 25, 2020.

7. Dandona L, Dandona R, Kumar GA, Shukla DK, Paul VK, Balakrishnan K, et al. Nations within a nation: variations in epidemiological transition across the states of India, 1990-2016, in the Global Burden of Disease Study. Lancet 2017;390(10111):2437-2460.

8. Apte K, Salvi S. Respiratory care therapists in chronic respiratory care: the need of the hour. Ind J Respir Care 2014;3(1):382-387.

9. Deshpande V. Respiratory therapy - global scenario. Ind J Respir Care 2012;1(1):3-7.

10. United States Department of Labor, Bureau of Labor Statistics. Occupational outlook handbook, respiratory therapists. 2020. Available at: https://www.bls.gov/ooh/healthcare/respiratory-therapists.htm. Accessed April 25, 2020

11. Shenoy A. Respiratory therapy in India - another step forward. Ind J Respir Care 2012;1(1):1-2.

12. Ministry of Human Resource Development, Department of Higher Education. All India Survey on Higher Education. 2019. Available at: https://mhrd.gov.in/aishe-report-2018-19. Accessed April 25, 2020

13. Ratnavelu V. Respiratory therapy in India. Ind J Respir Care 2012;1 (1):8-10.

14. Venkateswaran R. Importance of uniformity in education, continuing education and preparing tomorrow's leaders. Ind J Respir Care 2012;1 (1):11-14

15. American Association for Respiratory Care. Entry to respiratory therapy practice 2030. 2019. Available at: https://www.aarc.org/wp-content/ uploads/2019/09/issue-paper-entry-to-respiratory-therapy-practice-2030. pdf. Accessed April 25, 2020.

16. Barnes TA, Kacmarek RM, Kageler WV, Morris MJ, Durbin CG. Transitioning the respiratory therapy workforce for 2015 and beyond. Respir Care 2011;56(5):681-690.

17. National Board for Respiratory Care. Therapist multiple-choice examination detailed content outline. 2015. Available at: https:// www.nbrc.org/wp-content/uploads/2019/02/therapist-multiplechoice-dco-nbrc-website-effective-1-2015.pdf. Accessed June 10, 2018.

18. Carlin BW. Pulmonary rehabilitation and chronic lung disease: opportunities for the respiratory therapist. Respir Care 2009;54(8):10911099.

19. Spruit MA, Singh SJ, Garvey C, ZuWallack R, Nici L, Rochester C, et al. An official American Thoracic Society/European Respiratory Society statement: key concepts and advances in pulmonary rehabilitation. Am J Respir Crit Care Med 2013;188(8):e13-e64.

20. Bansal V, Gaur SN. Challenges of developing a pulmonary rehabilitation programme: practical aspects with India as a model country. Indian J Chest Dis Allied Sci 2016;58(2):89-91.

21. Bhome AB. COPD in India: iceberg or volcano? J Thorac Dis 2012;4 (3):298-309.

22. Shavro SA, Ezhilarasu P, Augustine J, Bechtel JJ, Christopher DJ. Correlation of health-related quality of life with other disease severity indices in Indian chronic obstructive pulmonary disease patients. Int J Chron Obstruct Pulmon Dis 2012;7:291-296.

23. Singh V, Khandelwal DC, Khandelwal R, Abusaria S. Pulmonary rehabilitation in patients with chronic obstructive pulmonary disease. Indian J Chest Dis Allied Sci 2003;45(1):13-17.

24. Vaishali K, Sinha MK, Maiya AG, Bhat A. The initial steps in pulmonary rehabilitation: how it all began. Lung India 2019;36(2):139-141. 